NASA Contractor Report 185279

AIAA-90-1968

\title{
High Energy-Density Liquid Rocket Fuel Performance
}

Douglas C. Rapp

Sverdrup Technology, Inc.

Lewis Research Center Group

Brook Park, Ohio

July 1990

Prepared for

Lewis Research Center

Under Contract NAS3-25266

\section{NASA}

National Aeronautics and

Space Administration

(NASA-CR-185279) HIGH ENFRGY-DENSITY LIQUID

N90-28742

ROCKET CUEL PERFORMANCE Final REPOrt

(sverdrup Technology) $14 \mathrm{p}$ 
$\checkmark \times$ 


\title{
HIGH ENERGY-DENSITY LIQUID ROCKET FUEL PERFORMANCE
}

\author{
Douglas C. Rapp* \\ Sverdrup Technology, Inc. \\ Lewis Research Center Group \\ Brook Park, Ohio 44142
}

\begin{abstract}
A fuel performance database of liquid hydrocarbons and aluminum-hydrocarbon fuels was compiled using engine parametrics from the space Transportation Engine Program as a baseline. Propellant performance parameters are introduced. General hydrocarbon fuel performance trends are discussed with respect to hydrogen-tocarbon ratio and heat of formation. Aluminum-hydrocarbon fuel performance is discussed with respect to aluminum metal loading. Hydrocarbon and aluminumhydrocarbon fuel performance is presented with respect to fuel density, specific impulse and propellant density specific impulse.
\end{abstract}

\section{Symbols}

c Carbon

go Gravitational constant $\left(9.80665 \mathrm{~m} / \mathrm{sec}^{2}\right)$

H Hydrogen

$\Delta H_{f p}$ Heat of formation of products (kcal/mole)

$\Delta H_{R}$ Heat of reaction (kcal/mole)

$\Delta H_{f r}$ Heat of formation of reactants (kcal/mole)

$I_{d}$ Density specific impulse (seconds)

$I_{\text {sp }}$ Sea-level epecific impulse (seconds)

m Number of Hydrogen atoms in a Hydrocarbon molecule

* Member, AIAA.

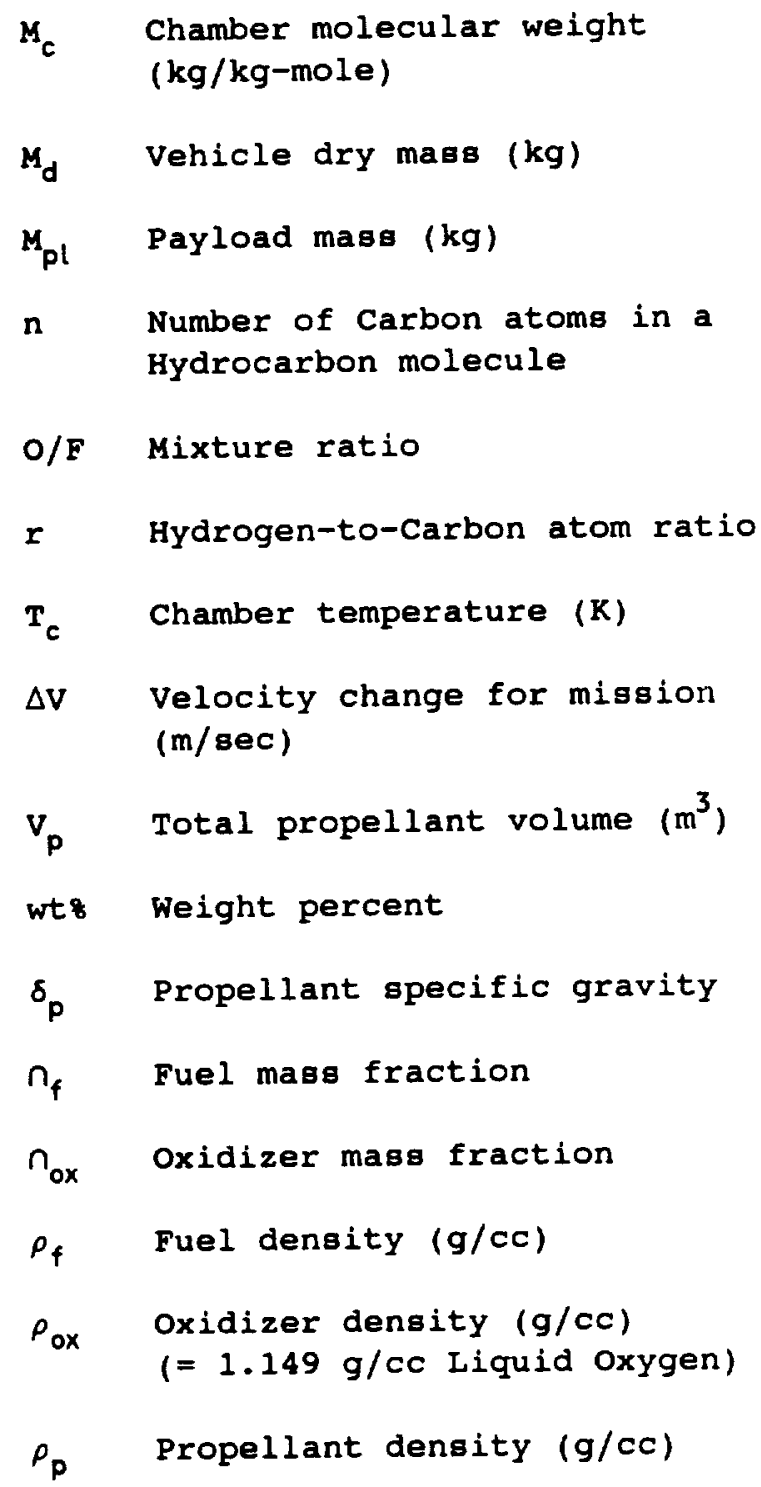

\section{Introduction}

The National Aeronautics and Space Administration (NASA) ir focusing on the development of advanced chemical rocket engines. These engines shall be required to operate at higher chamber pressures than the present space shuttle 
Main Engine. Higher chamber pressures will provide greater rocket engine performance. In general, the performance of propeliants has been documented for sea-level expansion from 1000 psia chamber pressure. The objective of this paper is to establish a propeliant performance database of liquid hydrocarbon and aluminumhydrocarbon fuels using advanced engine parametrics.

Interest in liquid hydrocarbon fuels has been maintained throughout the years simply because of the inherent ease of handling, long storage life, low toxicity, low cost and high density. Liquid hydrocarbons have been found beneficial in a number of liquid propellant rocket engines. For example, the largest liquid propellant rocket engine to date, the F-1 engine, employed a hydrocarbon, RP-1 (Rocket Propellant1, kerosene), ag the fuel and regenerative coolant. (1)

Hydrocarbon fuels have been evaluated in a number of NASA miseion studies as well. Migsion studies have focused on mixed-mode propulsion syetemg ${ }^{(2)}$, ginglestage-to-orbit vehicles ${ }^{(3-5)}$, liquid rocket boosters ${ }^{(6,7)}$ and new generation rocket engines for advanced space transportation systems ${ }^{(8-10)}$. Generally, the liquid hydrocarbon candidates evaluated in these studies have been methane, propane and RP-1. These fuels were singled out from the hydrocarbon fuel family for a number of reasons, including existing physical property and experience databases and their ready availability. NASA has, however, investigated alternate hydrocarbon fuels which would provide greater performance at a lower cost. These investigations considered constituents found in chemical and refinery streams, as well as synthetic hydrocarbons, and determined, some promising candidates. $(11,12)$

Metallized propellants have been considered as high energy-density materials for a number of years by NASA. (13) Metallized propellants are composed of a solid metaliic constituent stably surpended in either a liquid fuel, or liquid oxidizer. Metallized aluminum fuels are considered in this report. The addition of a metal to a liquid fuel increases the bulk fuel density. The performance of the fuel is potentially increased as well via the combustion energy input of the metal. Furthermore, the non-Newtonian rheological behavior of these fuels also serves to reduce tank sloshing and propellant leakage under tank rupture conditions. (14)

Recent propellant performance and mission studies have accentuated the benefits of employing this advanced chemical propulsion concept. Propellant performance increases have been documented with respect to mixture ratio and metal loading for beryllium, lithium and aluminum metallized propellants. (15) Aluminum and beryllium metallic additions to liquid bipropellant gystems were found to improve the performance of orbital transfer vehicle missions. (16) Additionally, metallized propellants offer benefits over conventional liquid bipropellant systems in planetary missions. (17,18) For instance, metallized propellants facilitate a 20 to 33 percent increase in delivered payload to the Marg surface ${ }^{(17)}$.

The objective of the analytical investigation presented in this paper is to establish a fuel performance database of hydrocarbon and aluminum-hydrocarbon fuels with advanced engine parametrics. A one-dimensional chemical equilibrium code was exercised to calculate performance parameters. (19) Actual hydrocarbon fuels evaluated include the three baseline fuels (methane, propane, $\mathrm{RP}-1$ ), recommended hydrocarbon fuels from previous investigations and high energy-density fuels from airbreathing propulsion. $(20-24)$ Aluminum is considered 
as a solid metallic fuel addition to the liquid fuels. Aluminum was selected since this metallic element was demonstrated in earlier studies (refs. 15-18) to increase specific impulse and delivered payload for specific missions.

For evaluating the performance advantages of these candidate fuels, the baseline engine parametrics $(2250$ poia chamber pressure, 40:1 area ratio, liquid oxygen oxidizer) of the present space Traneportation Engine Program (STEP) were used. Although this program is baselined hydrogen/oxygen $\left(\mathrm{H}_{2} / \mathrm{O}_{2}\right)$ propellants, the engine is the next generation Earth-to-Orbit rocket engine, and represents an excellent engine baseline for propellant comparison. Liquid hydrogen performance numbers are reported as well.

\section{Propellant Performance Parameters}

In order to quantify fuel performance, propellant performance parameters are required. Propellant density $\left(p_{p}\right)$, specific impulse ( $\left.I_{s p}\right)$ and density specific impulse $\left(I_{d}\right)$ are the propellant performance parameters used in this study. These parameters, introduced below, address the influence of the fuel and propellant properties on rocket engine and vehicle performance. The subsequent result sections report the quantitative performance results of the candidate fuels.

Fuel density $\left(\rho_{f}\right)$ contributes to the bulk propellant density $\left(\rho_{p}\right)$ through a mass fraction equation:

$\rho_{p}=1 /\left\{\left[n_{f} / \rho_{f}\right]+\left[n_{o x} / \rho_{o x}\right]\right\}$.

An increasing fuel density increases the propellant density magnitude. Greater propeliant densities contribute beneficially to vehicle performance as discussed below. All propellant densities in this report were calculated in accordance with equation 1 . The mixture ratio and, where applicable, the metal loading are accounted for in the mass fractions.

Heats of formation indicate the amount of energy required to form materials at specific temperatures and pressures. The fuel heat of formation contributes to the heat of reaction $\left(\Delta H_{R}\right)$ in the rocket engine chamber. The heat of reaction is related to the heat of formation of the reactants and products by the relation:

$\Delta H_{R}=\Sigma \Delta H_{f p}-\Sigma \Delta H_{\mathbf{f r}}$

Negative heats of reaction represent exothermic (energy release) processes. Consequently, increases in the fuel heat of formation will result in an increase in the heat of reaction and, in turn, a positive increase in the specific impulse (discussed below).

specific impulse is a rocket propellant performance parameter that represents the ratio of thrust generated to the weight flow rate of propellant. For an ideal, completely reacted gas (no dissociated products), this ratio is proportional to the square root of the chamber temperature $\left(T_{c}\right)$ and inversely proportional to the square root of the chamber molecular weight $\left(M_{c}\right)$. This relationship is presented in equation 3 .

$I_{s p} \propto\left(T_{c} / M_{c}\right)^{1 / 2}$

The specific impulse increases with higher combustion temperatures and lower molecular weight combustion products in the chamber. High opecific impulees are advantageous since greater thrusts are achieved at a fixed weight flow rate. Greater thrust-to-weight fractions can be generated, and more payload can be delivered to orbit as a result.

The effects of propellant density and specific impulse on vehicle performance 
(i.e., payload) can be qualitatively evaluated with the following equation:

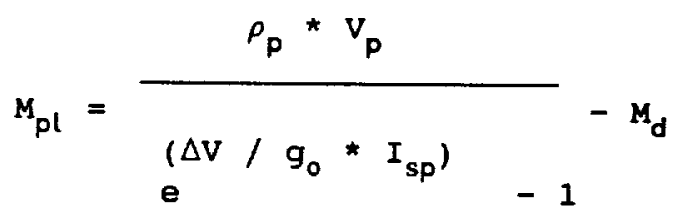

Increases in specific impulse and propellant density at fixed vehicle dry mass increases the payload capability of a vehicle. Syatem analyses for payload benefits were not conducted under this effort, and more detailed analyses will be required to determine the benefits for opecific vehicles.

In general, as propellant density decreases, the $I_{\text {sp }}$ increases. Since no one fuel can satisfy both high $I_{\text {sp }}$ and high density desires, a trade-off exists. The relative importance of each and their interrelationship with mixture ratio must be considered for each specific mission. To evaluate this influence, a propellant density specific impulse parameter is defined in equation 5 .

$I_{d}=\delta_{p} \star I_{s p}$

$\delta_{p}$ is the ratio of the propellant density to the density of liquid water, i.e. the propellant specific gravity. Increasing propellant density and specific impulse will increase the density specific impulse. A high density specific impulse is desired.

The density specific impulse parameter with varying exponential powers of $I_{s p}$ has been used in previous studies (refs. 5, 11, 12, 15) to evaluate vehicle performance and propellant performance. The precise $I_{\text {sp }}$ exponential power relies upon the particular mission's dependence on $I_{s p}$. The $I_{d}$ parameter at any specific impulse exponential power is arbitrary; however, it does allow for the evaluation of both propellant density and $I_{8 p}$ effects. The density specific impulse parameter reported in this study is used to qualitatively assess propellant density and $I_{s p}$ effects of hydrocarbon and metallized fuels and is not meant for comparison with liquid hydrogen .

In summary, high values of fuel and propellant densities, specific impulse and propellant density specific impulse are desirable. With this basic undergtanding of how rocket engine and vehicle performance is influenced by propellant properties, the analytical performance findings in the following result sections ahall be clearer to understand and interpret.

\section{Results}

\section{Liquid Hydrocarbon Fuel Performance}

Hydrocarbon fuels, by definition, are composed of two elemental constituents, carbon (C) and hydrogen (H) and are identified by the general molecular formula, $\mathrm{C}_{n} \mathrm{H}_{m}$. By employing the hydrogen-to-carbon ratio, $r(=\mathrm{m} / \mathrm{n})$, the general molecular formula was simplified to $\mathrm{C}_{1} \mathrm{H}_{\mathrm{r}}$. This simplification aids in identifying the influence of the hydrogen-to-carbon ratio on performance. within the results section of this paper, the general term "hydrocarbon" is indicated by $\mathrm{HC}$.

Seventy-one liquid HC fuels were analytically evaluated based on their fuel and propellant densities and specific impulse values. Propellant density was calculated using equation 1 and the mixture ratio of the chemical reactants. Performance values were generated from a one-dimensional chemical equilibrium code $(19)$ with shifting equilibrium at 2250 psia chamber pressure, supersonic area ratio expansion of 40 (STEP conditions) and a calculated mixture ratio for approximately maximum $I_{\text {sp }}$ (discussed below). The required program input of 
hydrogen-to-carbon ratio and reference enthalpy and temperature was compiled from references $2,5,11,12,18,19$, 21,23 and 25. Whenever reference enthalpies were unavallable, the heats of formation were determined from documented net (water vapor product) volumetric heats of combustion using the calculation method of ASTM Standard D $2382-88^{(26)}$.

The merit of candidate liquid $\mathrm{KC}^{\mathrm{s}} \mathrm{s}$ is measured by the fuel and propellant densities, specific impulse and the propellant density specific impulse product. The liquid HC's with the greatest fuel densities are compared to the baseline HC's and liquid hydrogen in Table 1. Superscript ( $(1)$, notations in Table 1 indicate HC's identified as readily available, low cost, liquid fuels obtainable from chemical and refinery plant streams. (11)

In general, fuel density increases with decreasing $r$. Of the seventy-one HC fuels evaluated, $39 \mathrm{HC}^{\prime} \mathrm{s}$ had greater fuel densities than the highest baseline HC, RP-1, at $0.80 \mathrm{~g} / \mathrm{cc}$. The highest density HC, H-COT-Dimer, represents a 42.58 increase in fuel density over RP1. Density advantages such as these will require further evaluation on a vehicle performance basis.

The specific impulse performance of HC fuels is influenced by the hydrogen-tocarbon ratio, $r$, and the fuel heat of formation. Applying equation 3 for specific impulse, the hydrogen-to-carbon ratio determines the oxidizer-to-fuel $(0 / F)$ mass ratio that approximately maximizes specific impulse. This maximum specific impulse is approximately realized at the stoichiometric $0 / F$ that produces the high energy release, low molecular weight reaction products, carbon monoxide $(\mathrm{CO})$ and water $\left(\mathrm{H}_{2} \mathrm{O}\right)$. The general chemical reaction and the equation indicating the otoichiometric mixture ratio for production of $\mathrm{CO}$ and
Table 1

Higheat Liquid Density Hydrocarbon Fuels

Fuel

Density

Hydrocarbon Formula (g/cc)

\begin{tabular}{|c|c|c|}
\hline H-COT-Dimer & $\mathrm{C}_{1} \mathrm{H}_{1.250}$ & 1.14 \\
\hline B-15 & $\mathrm{C}_{1} \mathrm{H}_{0.9170}$ & 1.10 \\
\hline RJ-5 & $C_{1} H_{1.286}$ & 1.08 \\
\hline$c-9(11)$ & $\mathrm{C}_{1} \mathrm{H}_{1.0656}$ & 1.07 \\
\hline $\begin{array}{l}\text { Tetrahydrotri- } \\
\text { cyclopentadiene }\end{array}$ & $\mathrm{C}_{1} \mathrm{H}_{1.467}$ & 1.04 \\
\hline $\begin{array}{l}\text { 1-Methy 1- } \\
\text { naphthalene }\end{array}$ & $\mathrm{C}_{1} \mathrm{H}_{0.909}$ & 1.025 \\
\hline $\mathrm{RJ}-6$ & $\begin{array}{ll}\mathrm{C}_{1} & \mathrm{H}_{1.417}\end{array}$ & 1.02 \\
\hline$c-3$ (11) & $\mathrm{C}_{1} \mathrm{H}_{1.3980}$ & 1.02 \\
\hline $\begin{array}{l}\text { B-20(mod.) } \\
\text { Baseline }\end{array}$ & $\mathrm{C}_{1} \mathrm{H}_{1.3586}$ & 1.00 \\
\hline $\mathbf{R P}-\mathbf{1}$ & $\mathrm{C}_{1} \mathrm{H}_{2.0}$ & 0.80 \\
\hline Propane & $\mathrm{C}_{1} \mathrm{H}_{2.667}$ & 0.5808 \\
\hline Methane & $\mathrm{C}_{1} \mathrm{H}_{4}$ & 0.43 \\
\hline Hydrogen (liquid) & $\mathrm{H}_{2}$ & 0.0709 \\
\hline
\end{tabular}

$\mathrm{H}_{2} \mathrm{O}$ are presented in Figure 1 . Increases in the fuel hydrogen-to-carbon ratio requires the stoichiometric $O / F$ ratio to increase.

The effect of an increasing hydrogento-carbon ratio (increasing mixture ratio) and HC heat of formation creates a positive enhancement in a propellant's attainable specific impulse. This enhancement occurs for two reasons. First, the average molecular weight of the combustion products decreases with increasing hydrogen-to-carbon ratio. second, increases in the hydrogen-tocarbon ratio (hence, mixture ratio) and HC heat of formation increases the heat of reaction. This heat of reaction increase results in a higher stagnation temperature thereby increasing specific impulse. These two explanations for improved specific impulse were confirmed through one-dimensional equilibrium performance calculations which also considers the effects of chemical dissociation and recombination.

The results of the performance gurvey 
are illustrated in Figure 2. The constant hydrogen-to-carbon ratio lines on the plot were generated with the onedimensional chemical equilibrium computer code with hypothetical HC fuels employing a constant hydrogen-to-carbon ratio and varying HC heat of formation per computer run. These constant hydrogen-to-carbon lines help to visualize the distribution of the seventy-one HC fuels also evaluated with the chemical equilibrium code. clearly, the majority of HC fuels are between $r=1$ and $r=2$ and have fuel densities less than $0.96 \mathrm{~g} / \mathrm{cc}$. Again, fuel densities are demonstrated to generally increase with decreasing hydrogen-to-carbon ratio.

The highest specific impulse $\mathrm{HC}^{\prime} \mathrm{s}$ are summarized with the baselined fuels in Table 2. Note that the liquid hydrogen performance was calculated at a mixture ratio of 6.0 , a space Transportation Engine Program condition. of the seventy-one HC fuels evaluated, $10 \mathrm{HC} \cdot \mathrm{s}$ had greater specific impulse than the highegt baseline HC, Methane, at 350.0 seconds. The highest specific impulse HC, Acetylene, represents a $5.8 \%$ increase in $I_{\text {sp }}$ over Methane. Liquid hydrogen offers a clear specific impulse advantage over all of the $\mathrm{HC}^{\prime} \mathrm{s}$ considered in this study.

Tabulations of the largest density specific impulse products are presented in Table 3. The high-density HC fuels dominate the listing. Of the seventyone HC fuels evaluated, 45 HC's had greater density specific impulse than the highest baseline HC, RP-1, at 341.7 seconds. The highest density specific impulse $\mathrm{HC}$, H-COT-Dimer, represents an 11.88 increase in $I_{d}$ over $R P-1$. Note that liquid hydrogen's $I_{d}$ is included for reporting purposes and should not be compared to the HC fuels on this basis. The relative importance of density and $I_{\text {sp }}$ must be considered for each specific application.

Table 2

Highest Specific Impulse Hydrocarbon Fuels Hydrocarbon Formula (seconds)

\begin{tabular}{|c|c|c|}
\hline Acetylene & $\mathrm{C}_{1} \mathrm{H}_{1}$ & 370. \\
\hline Allene & $\mathrm{C}_{1} \mathrm{H}_{1.333}$ & 156 \\
\hline $\begin{array}{l}\text { Bicyclo }(1,1,0)- \\
\text { butane }\end{array}$ & $\mathrm{C}_{1} \mathrm{H}_{1.5}$ & 356 \\
\hline Methylacetylene & $C_{1} H_{1.333}$ & 35 \\
\hline 1,5-Hexadiyne & $\mathrm{C}_{1} \mathrm{H}_{1}$ & 353 \\
\hline Ethylene & $\mathrm{C}_{1} \mathrm{H}_{2}$ & 353 \\
\hline $\begin{array}{l}\text { Cyclopropyl- } \\
\text { acetylene }\end{array}$ & $\mathrm{C}_{1} \mathrm{H}_{2.0}$ & 353 \\
\hline Spiro $(2,2)$ pentane & $\mathrm{C}_{1} \mathrm{H}_{1.6}$ & 351 \\
\hline 1,6-Heptadiyne & $\begin{array}{ll}\mathrm{C}_{1} & \mathrm{H}_{1.143}\end{array}$ & 350 \\
\hline $\begin{array}{l}\text { Cyclopropane } \\
\text { Baseline }\end{array}$ & $\mathrm{C}_{1} \mathrm{H}_{2}$ & 350 \\
\hline Hydrogen (liquid) & $\mathrm{H}_{2}$ & 432 \\
\hline Methane & $\mathrm{C}_{1} \mathrm{H}_{4}$ & 350 \\
\hline Propane & $c_{1}$ & 343 \\
\hline RP-1 & $\mathrm{C}_{1} \mathrm{H}_{2.0}$ & 337 \\
\hline
\end{tabular}

Table 3

Highert Density specific Impulse Hydrocarbon Fuels

Hydrocarbon Formula (seconds)

\begin{tabular}{|c|c|c|}
\hline $\mathrm{H}-\mathrm{COT}-\mathrm{D}$ imer & $C_{1} H_{1.25}$ & 382 . \\
\hline RJ-5 & $\mathrm{C}_{1} \mathrm{H}_{1.286}$ & 377.3 \\
\hline $\begin{array}{l}\text { Tetrahydrotri- } \\
\text { cyclopentadiene }\end{array}$ & $\mathrm{C}_{1} \mathrm{H}_{1.467}$ & 368.0 \\
\hline$R J-6$ & $\mathrm{C}_{1} \mathrm{H}_{1.417}$ & 366.1 \\
\hline $8-4^{(11)}$ & $\begin{array}{cc}C_{1} & H_{1.2430}\end{array}$ & 364.0 \\
\hline $\begin{array}{l}\text { Dicyclopropyl- } \\
\text { acetylene }\end{array}$ & $C_{1} H_{1.25}$ & 361.4 \\
\hline & $\mathrm{C}_{1} \mathrm{H}_{1.0656}$ & 361.1 \\
\hline $\begin{array}{l}\text { cis-trans } \\
\text { Perhydrofluorene }\end{array}$ & $C_{1} H_{1.692}$ & 360.9 \\
\hline $\begin{array}{l}\text { COT } \\
\text { (Cyclooctatetren } \\
\text { Baseline }\end{array}$ & $\begin{array}{l}C_{1} \mathrm{H}_{1} \\
\text { (e) }\end{array}$ & 360.4 \\
\hline $2 P-1$ & $\mathrm{C}_{1} \mathrm{H}_{2}$ & 341.7 \\
\hline opane & $\mathrm{C}_{1} \mathrm{H}_{2}$ & 309.3 \\
\hline ethane & $\mathrm{C}_{1} \mathrm{H}_{4}$ & 283.5 \\
\hline Jydrogen (liquid) & $\mathrm{H}_{2}$ & 156.7 \\
\hline
\end{tabular}


Aluminum-Hydrocarbon Fuel Performance Metallic additions to liquid fuels of fer increased fuel densities and the potential of increased propellant densities and performance. Aluminum was selected to demonetrate the advantages of metallic additions to liquid fuels because previous studies (refs. 15-18) indicated propellant and vehicle performance advantages when aluminum was employed. Based on the solid propellant industry, sixty-weight-percent (wtz) aluminum was considered the maximum metal loading. (18) Nine liquid HC fuels representing high specific impulse fuels, conventional high density fuels and the bageline fuels were evaluated in this effort. Note that liquid fuels without aluminum addition are indicated as "neat" liquids.

To determine the highest potential specific impulse for each aluminumliquid fuel combination, the mixture ratio and the weight percent of aluminum addition (i.e., aluminum loading) was varied. For any fixed metal loading, the mixture ratio for the aluminized fuels was considered "optimized" when the highest specific impulse was calculated using the one-dimensional chemical equilibrium code under the Space Transportation Engine Program conditions (2250 psia chamber pressure, 40:1 area ratio). The specific impulse peaks at a particular $0 / F$ and, subsequently, decreases with any shift in this mixture ratio. Hence, numerous mixture ratios were considered in order to identify the greatest specific impulse. This $I_{s p}$ optimization is illustrated in Figure 3 for the 5 wt 8 aluminum/RP-1 fuel, where the $I_{s p}$ maximizes at 341.7 seconds and mixture ratio of 2.5 .

Similarly, the aluminum loading was varied in five-weight-percent increments to identify a apecific impulse peak at each particular aluminum loading. Figure 4 depicts the peak specific impulse for the aluminum/RP-1 metallized fuel. The neat RP-1 fuel specific impulse was improved for metal loadings ranging from 5 to 40 weight percent aluminum, with maximum performance at 5 wt 8 aluminum. The mixture ratio for the highest specific impulse rises from 2.281 for neat RP-1 to 2.5 for 5 wto aluminum addition. The mixture ratio then gradually diminishes from the 2.5 value at 5 wto aluminum to 1.1 at 60 wto aluminum. In general, the highest-I mixture ratios for the metallized fuels above 10 wt aluminum were lower than the highest-I mixture ratio for the neat (i.e., non-metallized) fuels. These lower oxidizer-to-fuel ratios are attributed the increased metal content (decreased neat fuel content).

The quantitative performance results are presented in Tables 4 and 5 . Note that the metallized fuel and propellant densities, reported in Tables 4 and 5 , were calculated using equation 1 and accounted for the metal loading and the highest-I sp mixture ratio. With the exception of the aluminum-hydrogen propellant density, all fuel and propellant densities increased in magnitude with the addition of the dense, solid aluminum. The aluminumhydrogen propellant density decreased due to the dramatic decrease in mixture ratio from 6.0 to 0.6 . The aluminum-HC highest-I $I_{s p}$ mixture ratios decreased as well, however, these decreases were modest oince the neat fuel highest-I mixture ratios were initially low. The largest fuel density increase was the aluminum-hydrogen fuel at 1418 .

The greatest specific impulse enhancements through aluminum addition are graphically presented in Figure 5 and quantitatively oummarized in Table

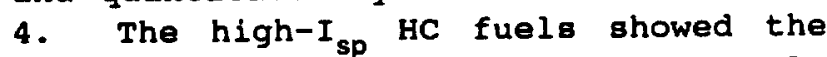
lowest specific impulse increases. As the $I_{s p}$ of the neat HC's decreased, the increase in $I_{s p}$ through aluminum addition became more significant. For instance, of the HC fuels considered, acetylene demonstrated no $I_{s p}$ increase with 
Table 4

Aluminum-Hydrocarbon Propellant $I_{\text {sp }}$ Performance lOptimum $I_{s p}$ weight percent aluminum, Maximum of 60 wts allowed)

\begin{tabular}{|c|c|c|c|}
\hline \multicolumn{3}{|c|}{ Metallized } & Metallized \\
\hline & Fuel & Neat Fuel & Propellant \\
\hline lase & $\begin{array}{l}\text { Density } \\
(g / c c)\end{array}$ & $I_{\text {sp }}$ & $I_{\text {sp }}$ \\
\hline
\end{tabular}

\begin{tabular}{|c|c|c|c|c|}
\hline 1 & $\ldots \ldots$ & 370.3 & * & $\ldots$ \\
\hline 2 & 0.778 & 356.3 & * & 356.4 \\
\hline 3 & 0.823 & 353.5 & * & 353.7 \\
\hline 4 & 0.951 & 334.1 & $\star \star$ & 339.7 \\
\hline 5 & 1.113 & 335.4 & $* *$ & 340.3 \\
\hline 6 & 0.971 & 332.9 & $\star \star$ & 338.8 \\
\hline 7 & 0.449 & 350.0 & $\star \star *$ & 351.9 \\
\hline 8 & 0.605 & 343.7 & $\star \star \star *$ & 346.8 \\
\hline 9 & 0.829 & 337.0 & $\star \star \star *$ & 341.7 \\
\hline 10 & 0.171 & 432.9 & $* * *$ & 443.9 \\
\hline
\end{tabular}

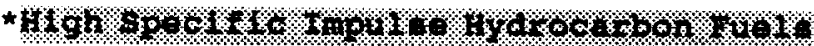

Case 1: Acetylene, $C_{1} H_{1}, O / F=1.843$,

aluminum loading $=0$ wt:

2: Bicyclobutane, $\mathrm{C}_{1} \mathrm{H}_{1.5}, \mathrm{O} / \mathrm{F}=2.0$

aluminum loading $=5$ wt:

3: 1,5-Hexadiyne, $\mathrm{C}_{1} \mathrm{H}_{1}, \mathrm{O} / \mathrm{F}=1.9$

aluminum loading $=5$ wt:

\section{*} ta. $1 \%$

Case 4: RJ-4, $C_{1} H_{1.667}, O / F=2.4$

aluminum loading $=5$ wt:

5: $\mathrm{RJ}-5, \mathrm{C}_{1} \mathrm{H}_{1.286}, \mathrm{O} / \mathrm{F}=2.2$

aluminum loading $=5$ wts

6: JP-10, $\mathrm{C}_{1} \mathrm{H}_{1.6}, \mathrm{O} / \mathrm{F}=2.4$

aluminum loading $=5$ wt:

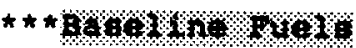

Case 7: Methane, $C_{1} H_{4}, O / F=3.1$

aluminum loading $=5$ wts

8: Propane, $\mathrm{C}_{1} \mathrm{H}_{2.667}, \mathrm{O} / \mathrm{F}=2.7$

aluminum loading $=5$ wts

9: $\mathrm{RP}-1, \mathrm{C}_{1} \mathrm{H}_{2}, \mathrm{O} / \mathrm{F}=2.5$

aluminum loading $=5$ wt:

10: Hydrogen (1iquid), $\mathrm{H}_{2}, 0 / \mathrm{F}=0.6$

aluminum loading $=60$ wto
}

Table 5

Aluminum-Hydrocarbon Propellant

$I_{d}$ Performance

(Optimum I $I_{\text {sp }}$ weight percent aluminum, Maximum of 60 wt: allowed)

\begin{tabular}{|c|c|c|c|}
\hline Care & $\begin{array}{l}\text { etallized } \\
\text { copellant } \\
\text { Density } \\
(g / c c)\end{array}$ & $\begin{array}{c}\text { Neat Fuel } \\
I_{d} \\
\text { (seconds) }\end{array}$ & $\begin{array}{l}\text { Metallized } \\
\text { Propellant } \\
I_{d} \\
\text { (seconds) }\end{array}$ \\
\hline 1 & $\ldots \ldots$ & 324.8 & $\ldots$ \\
\hline 2 & 0.991 & 348.8 & 353.3 \\
\hline 3 & 1.011 & 351.0 & 357.6 \\
\hline 4 & 1.083 & 355.8 & 367.8 \\
\hline 5 & 1.138 & 377.3 & 387.1 \\
\hline 6 & 1.090 & 356.9 & 369.4 \\
\hline 7 & 0.832 & 283.5 & 292.9 \\
\hline 8 & 0.924 & 309.3 & 320.6 \\
\hline 9 & 1.035 & 341.7 & 353.6 \\
\hline 10 & 0.251 & 156.7 & 111.5 \\
\hline
\end{tabular}

* Same Cases as Table 4.

aluminum addition, but JP-10, the lowest-I sp HC fuel considered, showed the greatest increase in $I_{s p}$ at 1.778 . The $I_{\text {sp }}$ of the aluminum-hydrogen fuel increased with higher aluminum loadings and demonstrated the greatest-I increase at 2.548 .

With the exception of acetylene, the specific impulse of the HC's peaked at the lowest aluminum concentration considered. A range of aluminum loadings exist, however, that improve $I_{s p}$ over that of the neat fuels (see Figure 4). This flexibility in aluminum loadings to produce improved specific impulse allows for the adjugtment of the metallized fuel and propellant densities based upon their importance to a specific mission.

Figure 6 and Table 5 present the density specific impulse effects of aluminum addition to the neat fuels. Density 
specific impulse increased in all of the liquid HC cases. Propane had the largest increase in $I_{d}$ at 3.658. The $I_{d}$ performance of the aluminum-hydrogen fuel is reported for completeness and should not be used for comparison with the HC fuels considered. Aluminumhydrogen $I_{d}$ decreased dramatically from 156.7 seconds to 111.5 seconds. This reduced density specific impulse is attributed to the marked decrease in mixture ratio from the baseline-sTEP condition of 6.0 to 0.6 at the 60 weight percent aluminum content. Again, the relative importance of propellant density and specific impulse must be weighed carefully for each mission profile.

\section{Conclusiong}

Hydrocarbon fuels offer high fuel and propellant densities. The greatest neat (non-metallized) fuel density is H-COTDimer at $1.14 \mathrm{~g} / \mathrm{cc}$. Additions of dense, solid metallic powders to neat fuels increase fuel densities and generally increase propellant densities. The major advantage of these metallized propellants is the reduction of vehicle dry mass due to smaller propellant tankage required or an increase in delivered payload at a fixed vehicle dry mass. Low aluminum additions ( 5 wt 8 ) to hydrocarbon fuels increase fuel densities by 3 to 4.58 . Large aluminum additions, however, dramatically increase fuel density. sixty-weightpercent aluminum increases the neat fuel density of liquid hydrogen by 1418 . Such high metal loadings may be stably suspended in neat fuels. (14)

The maximum specific impulse achievable with hydrocarbon fuels is 868 of the highest neat fuel, liquid hydrogen. Metallic additions to hydrocarbon and hydrogen fuels provide modest increases in specific impulse. Low aluminum additions (5 wty) maximize the hydrocarbon fuel specific impulse. For instance, the specific impulse of 5 wt?
aluminum/JP-10 is 332.9 seconds, an increase of 1.778 with respect to neat JP-10. The greatest increase in specific impulse through aluminum augmentation is liquid hydrogen at 2.54\%. Hydrogen's specific impulse increases with aluminum loading to 443.9 seconds at the maximum aluminum concentration considered (60 wt8).

The propellant density specific impulse qualitatively assesses the trade-off between propellant density and specific impulse. The maximum density specific impulse is $\mathrm{H}-\mathrm{COT}-\mathrm{Dimer}$ at 382.1 seconds. At the maximum specific impulse for metallized-hydrocarbon fuels (5-wt8 aluminum) the density specific impulse increases from 1 to 3.58 from that of the neat fuels. Larger increases in density specific impulse are feasible with higher metal loadings (higher densities) and a small reduction in specific impulse.

High energy-density propellants can advance rocket engine and vehicle performance through enhanced opecific impulse and propellant densities. An attractive fuel option for future high specific impulse applications is the aluminum/hydrogen fuel. For future high propellant density needs, the metallized, high-density hydrocarbon fuels are advantageous. The database of propellant performance properties establighed in this report, however, must be further analyzed. The relative importance of propellant density and specific impulse must be further defined to validate the merit of these propellants for specific misaions.

\section{Acknowledgment}

This work was supported by the NASA Lewis Regearch Center under contract NAS3-25266 with Ned P. Hannum as monitor. 


\section{Referenceg}

1. Warren, D. and Langer, C.; History in the Making - The Mighty F-1 Rocket Engine, AIAA 89-2387, July 10-12, 1989 .

2. Luscher, W.P. and Mellish, J.A.; Advanced High Pressure Engine Study for Mixed-Mode Vehicle Applications, NASA CR-135141, January 1977.

3. Beichel, R. and O'Brien, C.J.; Single-stage-To-Orbit Propulsion: Concepts and Their Merit, AIAA 78-974, July 25-27, 1978.

4. Martin, J.A.; Hydrocarbon Rocket Engines for Earth-to-orbit Vehicles, AIAA 81-1371, July 27-29, 1981.

5. Notardonato, J.J. and Masters, P.A.; High Density Propellant for single Stage to Orbit Vehicles, NASA TM X-73503, December 1976.

6. Wear, L.O.; Liquid Rocket Boosters for space Shuttle, AIAA 89-2622, July 10-12, 1989.

7. Visek, W.A.; LOX/Hydrocarbon Booster Engine Concepts; AIAA 86-1687, June $16-18,1986$.

8. Martin, J.A.; Space Transportation Main Engines for Two-stage Shuttles, AIAA 88-2929, July 11-13, 1988.

9. Martin, J.A. and Manski, D.; Variable-Mixture-Ratio and other Rocket Engines for Advanced Shuttles, AIAA 89-2282, July 10-12, 1989.

10. Stanley, D. and Talay, T.; Dual-Fuel Versug Single-Fuel Propulaion Syatems for AMLS Applications, AIAA 89-2504, July 1989.
11. Frankenfeld, J.W., Hastings, T.W., Lieberman M. and Taylor, W.F.; High Performance, High Density Hydrocarbon Fuels, NASA CR-159480, October 1978.

12. Wilson, J.N.; High Energy Hydrocarbon Booster Fuels, A Review and Theoretical Study, NASA CR-7243, September 1968.

13. Pinns, M.L., Olson, W.T., Barnett, H.C. and Breitwieser, R.; NACA Research on Slurry Fuels, NASA Report 1388, 1958.

14. Rapp, D.C. and Zurawski, R.L.; Characterization of Aluminum/RP-1 Gel Propellant Properties, AIAA-88-2821, July 1988.

15. Zurawski, R.L.; Current Evaluation of the Tripropellant Concept, NASA TP 2602, June 1986.

16. Zurawgki, R.L. and Green, J.M.; An Evaluation of Metallized Propellants Based on Vehicle Performance, AIAA-87-1773, June-July 1987.

17. Palaszewski, B.A.; Metallized Propellants for the Human Exploration of Mars, Case for Mars IV Conference, June 1990.

18. Palaszewski, B.A.; Lunar Missions Using Advanced Chemical Propulaion: System Design Issues, AIAA-90-2431, July 1990.

19. Gordon, S. and MCBride, B.J.; Computer Program for Calculation of Complex Chemical Equilibrium Compositions, Rocket Performance, Incident and Reflected Shocks, and Chapman-Jouguet Detonations, NASA-SP-273, 1971. 
20. Burdette, G.W.; Navy Ramjet Fuel Candidates, Naval Weapons Center, Reg. No. 4544-1031, June 1973.

21. Burdette, G.W., Iander, H.R. and MCCoy, J.R.; High Energy Fuels for Cruise Missiles, AIAA 78-267, January 16-18, 1978 .

22. Burdette, G.W.; Navy Airbreathing-Misaile Fuels Program, High Energy Hydrocarbon Fuels Workshop, November 17-18, 1981.

23. Burdette, G.W.; Survey of Work on Liquid Fuels for Airbreathing Missiles.

24. MCCOY, J.R.; Liquid Airbreathing Missile Fuels: An Overview of Properties and Applications, 1980 JANNAF Propulsion Meeting, Vol. 5, 613-619.

25. Smith, N.K. and Good, W.D.; Enthalpies of Combustion of exo-THDCP, RJ-4, Igomer RJ-4, JP-9; AFOSR-TR-78-1069; Bartelsville Energy Regearch Center, June 1978.

26. ASTM standard D 2382-88; standard Test Method for Heat of Combustion of Hydrocarbon Fuels by Bomb Calorimeter (High-Precision Method).
Figure 1. Mixture Ratio vs. Hydrogen/Carbon Ratlo

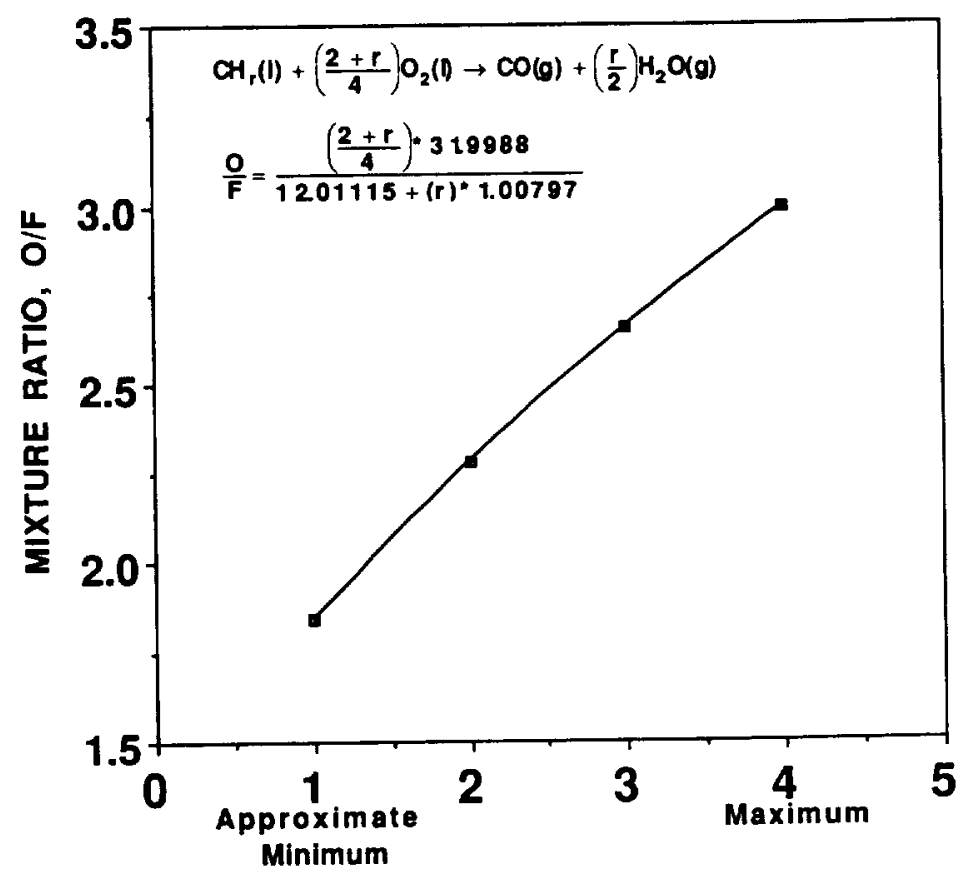

HYDROGEN / CARBON RATIO, $r$

Figure 2. Speciflc Impulse vs. Heat of Formation

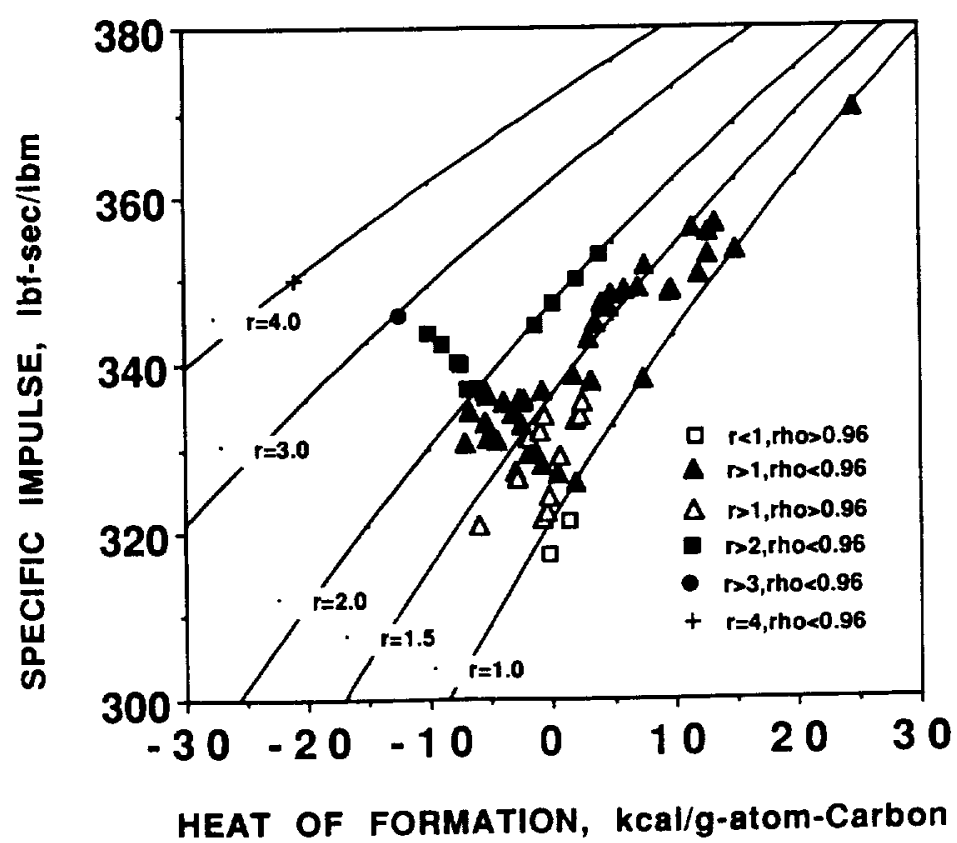


Figure 3. Peak Speciflc Impulse Based on Mixture Ratio (5 wt\% Aluminum Loading in RP-1)

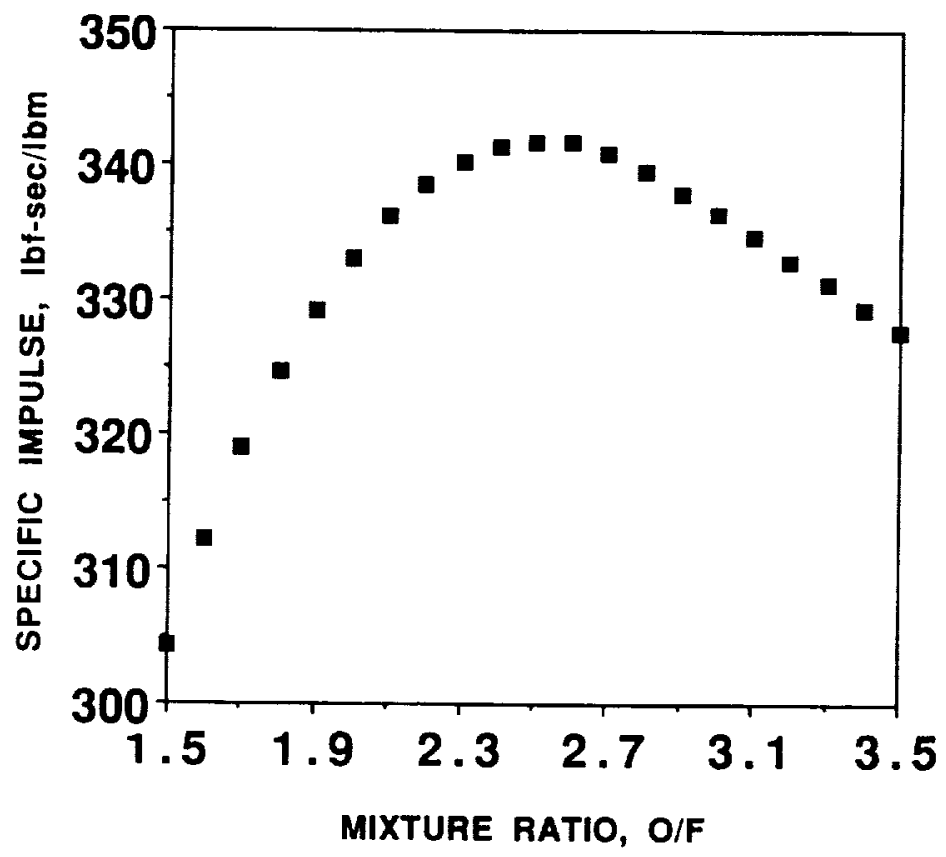

Flgure 5. Aluminized Propellant Maximum Speciflc Impulse Performance

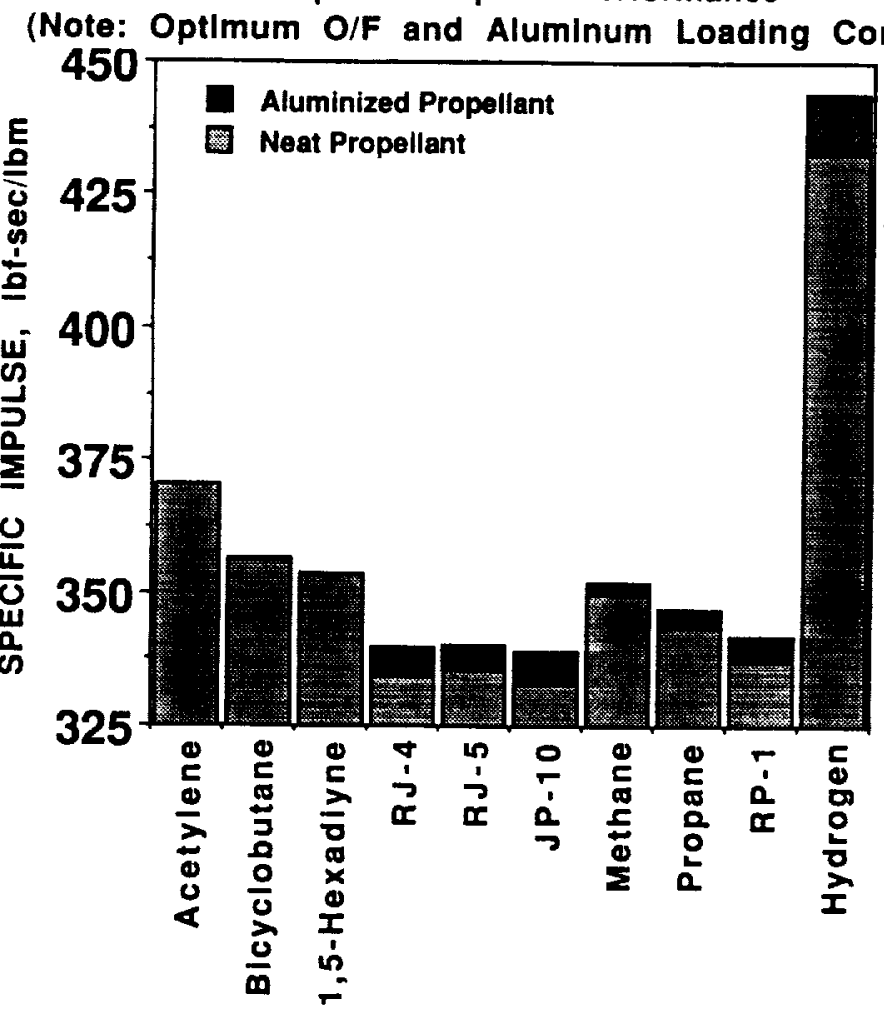

LIQUID FUEL
Figure 4. Peak Specific Impulse Based on Aluminum Loading In RP.1

(Note: Mixture Ratio differs at each Metal Loading)

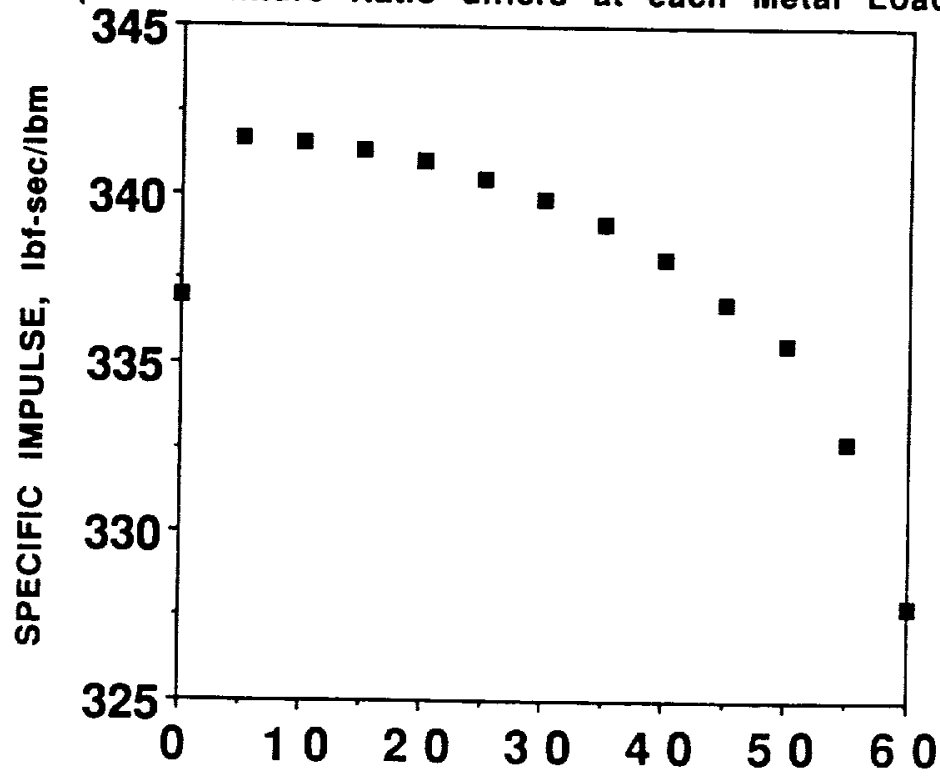

ALUMINUM LOADING IN RP-1, wt\%

Figure 6. Aluminized Propellant Density Specific Impulse Performance (Note: Maximum Isp Condition)

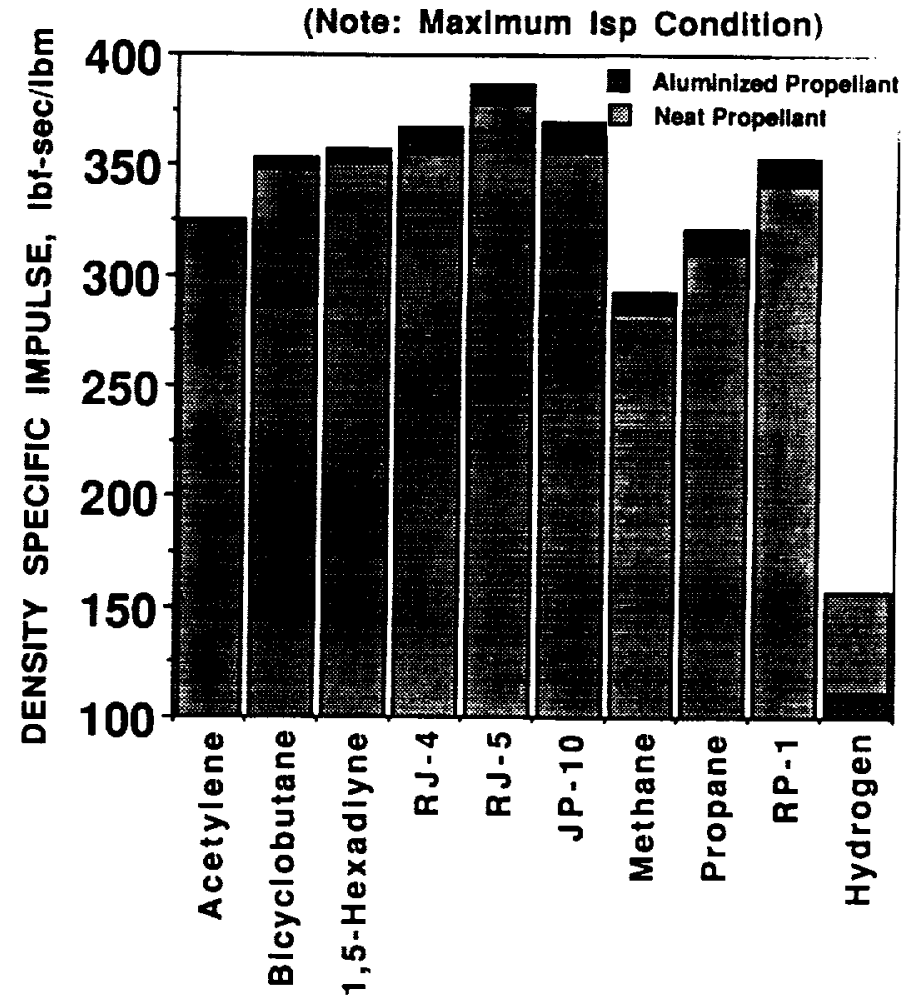

LIQUID FUEL 


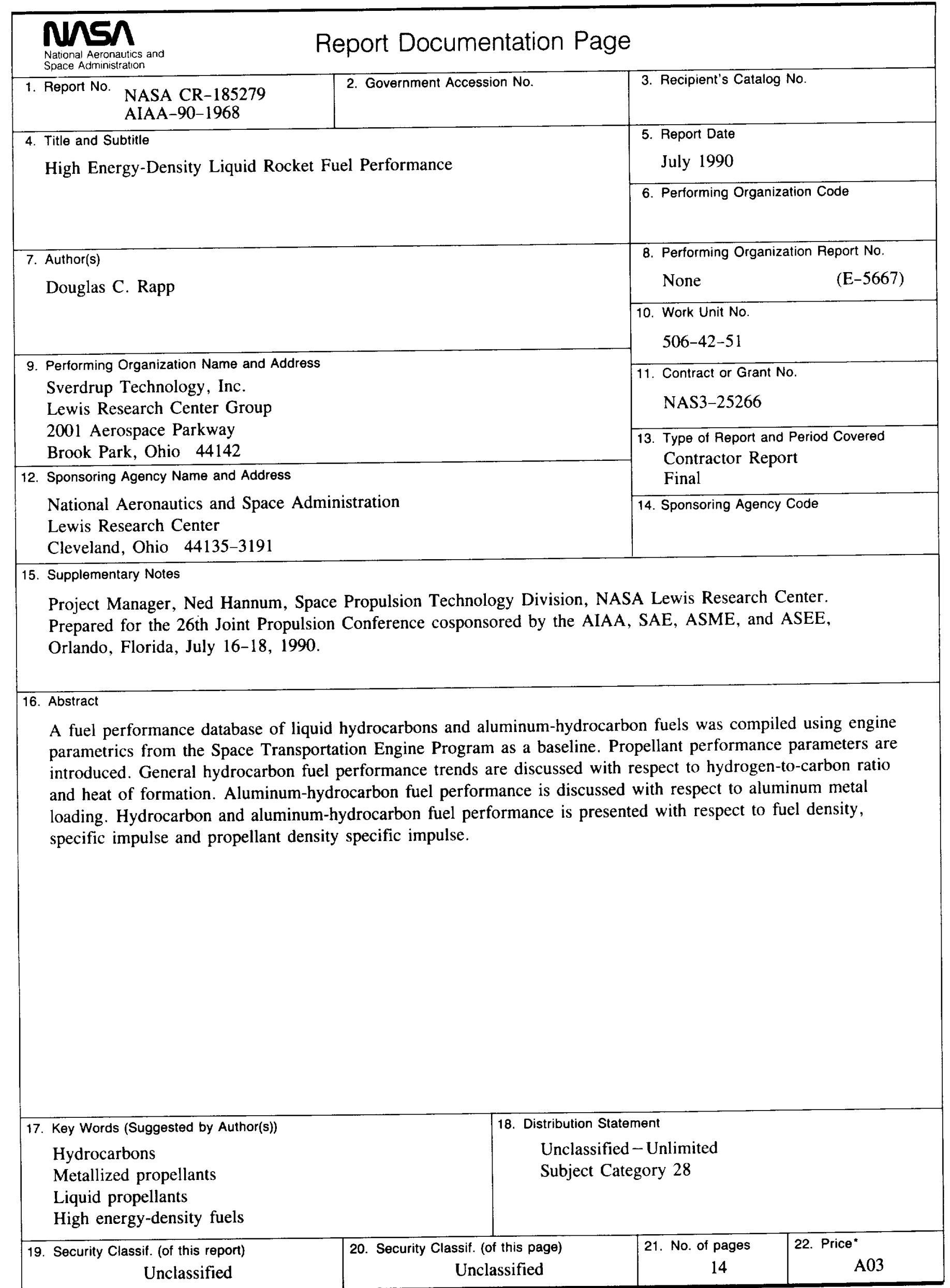


National Aeronautics and Space Administration

Lewis Research Center Cleveland, Ohio 44135

Otficial Business

Penalty for Private Use $\mathbf{5 3 0 0}$
FOURTH CLASS MAIL

ADDRESS CORRECTION REQUESTED
|||||

Posiagenang Feer fourt

Natonial Aeronautios and

Spicendminict:dtrm

NASA 45 